OPEN ACCESS

Edited by:

Ricardo Baldi,

Centro Nacional Patagónico,

Argentina

Reviewed by:

Darryl Jones,

Griffith University, Australia

Varun R. Goswami,

Wildlife Conservation Society, India

${ }^{*}$ Correspondence:

Joshua M. Plotnik

Joshua.Plotnik@gmail.com

Specialty section

This article was submitted to

Conservation,

a section of the journal

Frontiers in Ecology and Evolution

Received: 04 May 2018

Accepted: 26 July 2018

Published: 20 August 2018

Citation:

Mumby HS and Plotnik JM (2018) Taking the Elephants' Perspective: Remembering Elephant Behavior,

Cognition and Ecology in

Human-Elephant Conflict Mitigation

Front. Ecol. Evol. 6:122.

doi: 10.3389/fevo.2018.00122

\section{Taking the Elephants' Perspective: Remembering Elephant Behavior, Cognition and Ecology in Human-Elephant Conflict Mitigation}

\author{
Hannah S. Mumby ${ }^{1,2}$ and Joshua M. Plotnik ${ }^{3,4 *}$ \\ ${ }^{1}$ Department of Zoology, University of Cambridge, Cambridge, United Kingdom, ${ }^{2}$ College for Life Sciences, \\ Wissenschaftskolleg zu Berlin, Berlin, Germany, ${ }^{3}$ Department of Psychology, Hunter College, City University of New York, \\ New York, NY, United States, ${ }^{4}$ Psychology Program, The Graduate Center, City University of New York, New York, NY, \\ United States
}

Conflict between humans and wildlife is an increasing problem worldwide due to human population growth and habitat fragmentation, with growing interest amongst scientists and conservationists in developing novel solutions toward sustainable coexistence. Current efforts to mitigate human-wildlife conflict, however, are often unbalanced; they consider immediate human-centric concerns and offer deterrents against wildlife, rather than offering solutions to the underlying problems. Recently, there has been an increase in the number of calls to action for the integration of animal behavior, cognition and knowledge of individual variation into conservation practice. However, as elephant researchers, we have seen that most human-elephant conflict mitigation strategies employed in Asia and Africa are based on conditioning fear in elephants, or general monitoring of individual or group activities aimed at altering elephant movements, rather than understanding and providing for elephant and human needs. We see an opportunity to do more by investigating elephant behavior, cognition and ecology at the level of the individual to prevent conflict from occurring in the first place. Here, we review studies on elephants to illustrate this concept and to outline avenues for the application of research on elephant ecology, life history, behavior and personality to the development of new, comprehensive conservation strategies that take both human and elephant behavior into account.

Keywords: Loxodonta africana, Loxodonta cyclotis, Elephas maximus, conservation, mitigation, animal behavior, conservation behavior

\section{INTRODUCTION}

A number of rallying cries have been issued to challenge scientists working on animal behavior to think about the conservation applications of their work. However, there has been limited action to integrate results of such work into the design and implementation of conservation measures (Caro, 2007; Caro and Sherman, 2013; Greggor et al., 2014; Berger-Tal et al., 2015; Barrett et al., in press). In applied conservation science, the needs, societal context, culture and behavior of individuals and groups of people are essential factors in the human-centered models that dominate the field's landscape (Dickman, 2010). We see the need for a clear plan that also recognizes and applies 
these factors to wildlife. When animal behavior research is applied to conservation in practice, it can be successful because it pays careful attention to the underlying causes of the problem from the affected animal's perspective [observing preydriven antipredator behavior to locate endangered predatorsAle and Brown (2009); e.g., attention to social dynamics in translocations-Shier and Swaisgood (2012); understanding how animals learn from each other in order to manage successful releases into the wild-Berger-Tal and Saltz (2014)]. Here, we focus on one particular conservation issue that centers on the interactions between humans and one significant umbrella megafauna, the elephant.

Human-elephant conflict (HEC) is a term used to describe the variety of negative, physical interactions between humans and elephants. Perceptions and fear associated with the conflict also go far beyond the direct interactions and make mitigation a challenge. In fact, human-elephant conflict flashpoints range widely. They may have an agricultural, environmental and/or financial impact related to crop-raiding or foraging (King et al., 2011; Chiyo et al., 2012; Wilson et al., 2015), damage to property and water and grain stores (Wilson et al., 2015), and impacts on vegetation (Midgley et al., 2005). They may also have a direct impact on the different parties' lives, manifested in the perceived effects of the conflict on human wellbeing (Barua et al., 2013), injury and death of humans and livestock, and retaliatory killing of elephants by humans (Dunham et al., 2010). How often and where each of these events occurs varies widely in Africa and Asia alongside variation in environmental factors such as resource distribution, agricultural practices, human occupation of land, seasonal climatic conditions and habitat connectivity (Bal et al., 2011; Cook et al., 2015; Goswami et al., 2015; Wilson et al., 2015).

For some, the term "conflict" itself is inherently problematic because it suggests an adversarial dynamic and exacerbates tensions, implying that interactions are always negative and that the needs of the different species must be mutually exclusive (Peterson et al., 2010). Some suggest that "coexistence" is a better term because it highlights the fact that positive relationships can and do exist between species living in the same habitats and landscapes (Hoare and Du Toit, 2001; Carter et al., 2012; Songhurst et al., 2016). It is clear, however, that humans and elephants do often compete for resources and are often involved in agonistic interactions across both African and Asian landscapes (Hoare, 2012). Interestingly, the intensity and type of these interactions vary widely, suggesting that there are differences not only across landscapes but also within individuals involved. Understanding the diversity and flexibility of both positive and negative interactions between humans and elephants, as well as the behavior of both are essential for ensuring that conservation practitioners can address all parties' concerns and develop comprehensive policy effectively.

Here, we discuss how the fields of elephant behavioral ecology and comparative cognition as examples can and should be used in the development of comprehensive conservation strategy, specifically human-elephant conflict mitigation action plans in Asia and Africa. We believe this can be accomplished by: (1) applying knowledge of individual variation in life history, personality and behavior to specific, local contexts and (2) taking into account the cognition and sensory perspectives of elephants when developing future conservation strategies. From our point of view, the imperative to take the "elephants' perspective" to prevent conflict between humans and elephants requires that the high resource needs of all parties are satisfied. Unfortunately, the fulfillment of human needs at the expense of the elephants' only delays conflict. Mitigation strategies aimed at preventing conflict by creating physical barriers to it will not, by themselves, solve conflict in the long-term. These strategies neglect details about the landscape in which the conflict occurs, as well as consideration for the individuals involved and their relevant behavior.

One major contributing factor is that the social, physiological and environmental needs of humans and non-human animals are often framed as being opposed to one another, rather than potentially overlapping (Dublin and Hoare, 2004; Barua, 2014). For instance, in the social context, elephants are generally regarded, like humans, as cognitively complex, socially intelligent animals that display empathy toward and learn socially from conspecifics (Lee and Moss, 1999; Plotnik and de Waal, 2014). Elephants cooperate with each other (e.g., McComb et al., 2001, 2011; Plotnik et al., 2011), and there are several anecdotal examples from wild studies of specific targeted helping behaviors in relation to deceased conspecifics and empathy (McComb et al., 2005; Douglas-Hamilton et al., 2006; Bates et al., 2008a). In a physiological context, the pressures on humans and elephants to acquire resources, support the energetic requirements of large bodies and brains over a long life and provisioning offspring means that the resource requirements of both species are high (Shannon et al., 2008; Reiches et al., 2009; Langman et al., 2012).

Long-term research on the complex ecology and life histories of individually identified elephants shows that they exhibit individual-level variation, for example, in responses to changing environmental conditions such as adjusting growth and reproduction in response to droughts (Lee et al., 2011) or workload (Mumby et al., 2015). This individual variation is in addition to age and sex-specific behavior, such as males having different home range use than females because of hormonal changes specific to their sex such as "musth" (Charif et al., 2004). These patterns of variation can inform us about both the elephants' effect on the landscape in relation to humans (Cook et al., 2015; Goswami et al., 2015), as well as the impact of human disturbance on the elephants' social systems (Goldenberg et al., 2016).

Research using individual observations on elephant social intelligence and the complexity of their social relationships (e.g., de Silva et al., 2011; McComb et al., 2011; Plotnik et al., 2014), as well as our growing understanding of how elephants use non-visual sensory modalities -i.e., olfaction and audition (Poole et al., 2005; Bates et al., 2007a,b; McComb et al., 2014; Plotnik et al., 2014; Von Dürckheim et al., 2018)—complements life history and ecological research by suggesting that how elephants make decisions may also play a role in the flexibility of environmentally-dependent behavior (Srinivasaiah et al., 2012). Information about how individuals and groups navigate their physical and social environments has direct implications for our 
understanding of what causes, and what can mitigate conflict (Chartier et al., 2011).

\section{CURRENT HEC MITIGATION STRATEGIES}

One interesting and problematic commonality across many current human-elephant conflict mitigation techniques is their foundation in fear conditioning. This usually includes, for example, the use of negative stimuli such as electric fencing and hand-held firecrackers to force elephants away from crops (Figure 1). Table 1 shows the range of mitigation measures employed, with a majority of the strategies largely focused on the use of a negative stimulus. Most strategies use barrier methods, which have been developed to prevent elephants from accessing crops or areas used by humans. Even softer measures such as coating fences in chili peppers (Osborn and Parker, 2002; Le Bel et al., 2015) or using bees to deter elephants (King et al., 2011) involve "persuading" the animal to avoid a potentially negative experience. These strategies, although potentially effective when consistently implemented and maintained long-term, may be incomplete in their incorporation of what we know (and what we still need to learn) about individual variation and behavior in elephants. The other significant issue is that all strategies need to take the space, landscape and resource needs of both humans and elephants into account (Goswami and Vasudev, 2017); when the needs of the latter are neglected, the mitigation plans are prematurely set up to fail.

In Sri Lanka, for example, pilot programs in which citrus crops are grown that are (a) unappealing to elephants and therefore do not encourage elephants to raid and (b) do not rely on fear-based conditioning to keep the elephants away have been successful (Sri Lanka Wildlife Conservation Society, 2015). In addition to this strategy being feasible at the scale of individual farms, the fruits can be sold for a profit and the rice crops can be grown behind the barrier of citrus trees. Although promising, this mitigation strategy, like most others, relies on the assumption that the primary reason for elephant crop-raiding is access to food; potentially, this is only a secondary by-product of the elephants' migration needs, limited space available in protected areas, the demography of the population and dispersal patterns of male elephants, or some other variable that has not yet been identified (Jackson et al., 2008). This is yet another reason why the collection of baseline behavioral and demographic data for the elephant populations in a given area is essential, as is the need to collect land usage data on individual elephant groups across diverse landscapes. Progress is also being made regarding the use of elephant communication to better inform humans about the presence of elephants and to provide early warnings in areas of human-elephant conflict (for example, by detecting their infrasonic rumbles-Zeppelzauer and Stoeger, 2015).

Thus, whilst together these different strategies represent an important step forward in the monitoring of potential conflict, they only treat conflict "symptoms" with temporary fixes and neglect to address the underlying causes of potentially systemic conflict. The strategies involving negative stimuli largely require elephants to balance the negative experience of the mitigation strategy against potential gains of the conflict activity and only remain effective if the elephants continue to avoid an everpresent negative stimulus. In addition, these monitoring methods and mitigation strategies do not aim to directly alter or impact elephant behavior in a positive way, but only focus on physical, acoustic or olfactory barriers between elephants, humans and their habitats.

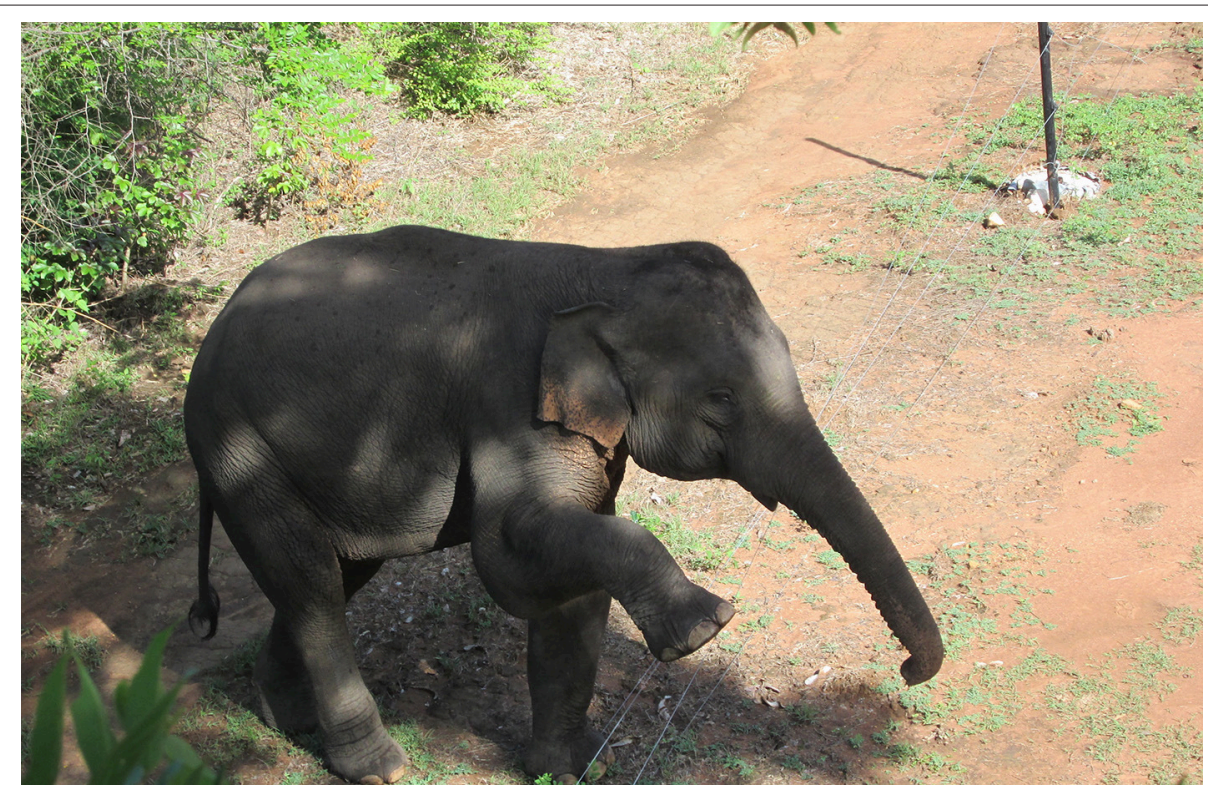

FIGURE 1 | Teenage male elephant stepping over non-live electric fence in Kanchanaburi, Thailand. Regular maintenance of mitigation methods like electric fences is crucial with elephants, as they learn quickly about the lack of consequences when the fences are inactive. Photograph published with permission from the Zoological Society of London. 
TABLE 1 | Methods of human-elephant conflict mitigation currently employed in Asia and Africa.

\begin{tabular}{|c|c|c|}
\hline Method & Examples & Links to elephant behavior and ecology \\
\hline Fencing methods & $\begin{array}{l}\text { Barbed wire or chain link (Hoare, 2003; Fernando et al., 2008), } \\
\text { stone or log (Hoare, 2003; Fernando et al., 2008), electric (Osborn } \\
\text { and Parker, 2002; Hoare, 2003; Kioko et al., 2008; Asimopoulos, } \\
\text { 2016), chili pepper paste applied to rope (Fernando et al., 2008; } \\
\text { Wiafe and Sam, 2014; Wahed et al., 2016), beehives on fences or } \\
\text { trees (Ngama et al., 2016; King et al., 2017; Cook et al., 2018). }\end{array}$ & $\begin{array}{l}\text { Some are aimed at preventing elephant movements, while others } \\
\text { use a repellent such as electricity, chili pepper or bees to elicit a } \\
\text { fear response. Habituation could become an issue with all of these } \\
\text { methods. }\end{array}$ \\
\hline Repellents & $\begin{array}{l}\text { Chili pepper gas disperser (Le Bel et al., 2015), burning chilies and } \\
\text { dung (Osborn and Parker, 2002), chili bombs (dried chilis } \\
\text { combined with dung and water) (Jones and Elliott, 2006), vehicular } \\
\text { disturbance (Hahn et al., 2016), pipe cannon (Asimopoulos, 2016), } \\
\text { burning wood or bamboo (Osborn and Parker, 2002; Fernando } \\
\text { et al., 2008), spotlights (Zimmermann et al., 2009; Raihan Sarker } \\
\text { and Røskaft, 2010). }\end{array}$ & $\begin{array}{l}\text { These methods aim to elicit a fear response that may increase } \\
\text { conflict or encourage long-term habituation by the elephants to } \\
\text { negative stimuli. }\end{array}$ \\
\hline Human strategies & $\begin{array}{l}\text { Surveillance methods such as local people recording and } \\
\text { monitoring conflict incidents (Osborn and Parker, 2002; } \\
\text { Zimmermann et al., 2009; Wahed et al., 2016; Gunaryadi et al., } \\
\text { 2017) and occupying watchtowers (Fernando et al., 2008; Wahed } \\
\text { et al., 2016). More active monitoring such as hiring guards } \\
\text { (Fernando et al., 2008), and using captive elephants ridden by } \\
\text { humans to drive away wild elephants (Fernando et al., 2008). } \\
\text { Human-focused solutions such as monetary compensation for } \\
\text { damage, injury or death resulting from conflict (Distefano, 2005). }\end{array}$ & $\begin{array}{l}\text { Surveillance is more focused on preventing and monitoring } \\
\text { conflict, and compensation is human-focused. Driving away } \\
\text { animals and guarding crops may elicit fear responses from the } \\
\text { elephants that either increase the frequency of physical } \\
\text { altercations or result in the elephants finding alternative access } \\
\text { points to crops. }\end{array}$ \\
\hline Removing elephants & $\begin{array}{l}\text { Relocating elephants (Asimopoulos, 2016), killing "problem" } \\
\text { elephants (Nelson et al., 2003), culling (Van Aarde et al., 1999). }\end{array}$ & $\begin{array}{l}\text { Removal takes into account that elephants may habitually become } \\
\text { involved in conflict but neglects the fact that moving problem } \\
\text { elephants to other areas may lead to the spread of problematic } \\
\text { behavior to conspecifics via social learning. }\end{array}$ \\
\hline
\end{tabular}

Methods have been grouped by strategy, focusing on fencing, perimeters, humans and elephants, with examples of each strategy provided. We also describe the methods' links to behavior and ecology. Although not a fully exhaustive list, these examples highlight the importance of an elephant perspective in HEC mitigation and prevention.

In order to better provide mitigation solutions, we must take into account both human and animal motivations for engaging in potentially risky conflict-causing activities. For example, evidence suggests that elephants that consume agricultural crops are not only accessing calorie-dense food sources, but that they also grow larger than their non-raiding conspecifics (Chiyo et al., 2011). This means that their behavior may be linked to fitness benefits, as dominance and access to mates is linked to body size (Sukumar and Gadgil, 1988; Chiyo et al., 2011). On the human side, farmers have to balance costs of investing in mitigation measures against the value of compensation (Jackson et al., 2008), as well as the social and community-level impact of the conflict. The balancing act maintained by both elephants and humans cannot be seen as static, but in flux because of variation including seasonal availability of resources, social factors and mortality. Any inputs into the system, such as providing farmers with new mitigation tools or compensation could influence this balance in different ways, including stimulating further conversion of land to agricultural use (Bulte and Rondeau, 2005). This suggests that each HEC landscape, even within the same country or region, must be assessed as a unique case with a unique set of confounds and needs for both the individual elephants and the humans involved.

\section{INFORMING HEC MITIGATION}

Here, we suggest a holistic approach that focuses on both human and elephant factors. In areas where no mitigation strategy has yet been employed, a careful evaluation of human and elephant behavior and culture should be conducted first, hence the need for collaboration across disciplines in biology, psychology, anthropology and ecology at this level. For instance, both the social dynamics and landscape use of the humans and the elephants must be considered in HEC mitigation (Hoare, 2012); thus, effective strategies would require different types of academic and local community-level expertise.

First, at the level of the community, villages with stable community leaders and good relations between local members may find success with mitigation strategies that require collaboration over large distances (e.g., maintaining several kilometers of electric fence-Wilson et al., 2015). In communities with significant social strife or a lack of cooperation between individuals, attempts at resolving within-group disagreements should be made first to ensure the viability of any HEC mitigation strategy that requires long-term, cooperative investment from all stakeholders. If a mitigation strategy has already been employed and works in a particular site, the strategy's long-term 
potential requires that it be applied consistently (for instance, by encouraging community members to be responsible for the upkeep of the specific sections of the electric fence that traverse their land-Chartier et al., 2011). Focusing on consistency in the implementation and maintenance of specific mitigation strategies encourages cooperation among local people but also sends a consistent message to the elephants in their environment. This awareness within human communities, the use of local knowledge and strong local collaborations are vital to the success of interventions or mitigation techniques.

The human dynamic is only one piece, of course; there is a crucial need for a more comprehensive, ecological and psychological understanding of the elephants' behavior and its environmental context. The most important questions we should ask center on why the elephants are coming into conflict with humans, and whether there are individual differences between elephants within and across populations that make them more or less likely to engage in such conflict. We propose to address these questions using two complementary areas of research: the study of elephant behavior and cognition, and the study of elephant ecology and life history. Studies conducted both in Africa and Asia, with both captive and wild populations, show clear evidence for individual differences in a number of ecological and cognitive categories, including parasite load (Lynsdale et al., 2017), body size (Evans and Harris, 2012; Chapman et al., 2016), primiparity (Crawley et al., 2017), social hierarchy (McComb et al., 2011), innovation (Bates et al., 2008b), cooperation (Plotnik et al., 2011), problem-solving (Foerder et al., 2011), aggression (Poole, 1989), and personality (Lee and Moss, 2012; Yasui et al., 2012; Seltmann et al., 2018). Identifying whether or not specific behavioral, physical, demographic or personality traits (collected through future ecological, ethological and experimental research on captive and wild elephants) correlate with an elephant's propensity to crop-raid or engage in conflict may have important implications for preventing or managing these conflicts across different landscapes.

Our growing knowledge about the complexity of elephant cognition and the variability in life history traits suggests that there are most likely substantial differences across populations and between individuals in their propensity for risk taking (Hoare, 1999). For example, from the cognitive perspective, while in-conflict elephant groups in which the leader or other adults are risk averse, fearful of humans or neophobic may only require simple mitigation approaches, areas with risk prone, innovative, curious, or destructive elephant groups may require a more aggressive mitigation strategy to curb conflict. Equally as relevant, these behavioral traits might be linked to life history characteristics such as age, sex, reproductive state or other demographic or ecological traits. Thus, our aim is to gain a comprehensive picture of the individuals in the study area as well as the leadership structure within these groups (McComb et al., 2001, 2011; Wittemyer et al., 2007; de Silva and Wittemyer, 2012) in order to develop protocols that are thus both local communityand elephants-specific and seek positive outcomes from potential conflict scenarios.

In future research, scientists could collect both demographic and trait-based data at the individual level. These data would not be focused simply on the animal's life history stage or sex alonesuch as when dispersing adolescent males show a propensity to crop forage or raid (Sukumar and Gadgil, 1988; Rode et al., 2006; Chiyo et al., 2011, 2012) - but would also take into account the size, mortality risk, reproductive status, health status and use of resources of the individual as well as seasonal variation within each. Such research would complement data gathered from ethological (direct, systematic field observations of elephants close to or within crop-raiding zones) and experimental research designs. In the latter, basic cognitive tasks set up in areas frequented by wild elephant groups could help identify individual differences across elephants in confidence, innovation, riskpropensity, leadership and neophobia. Together, this work could be used to develop demographic, physical and personality profiles for individual elephants and groups, which could then be used to inform the implementation of area, group- or elephant-specific strategies to prevent conflict. If the reasons for differences in the type and level of conflict within and across range countries is not purely due to landscape and habitat differences, but instead has demographic, behavioral or personality-level implications, then focusing on influencing the elephants' decision-making process may be a novel approach to mitigating the conflicts across countries. For instance, by focusing on how elephants find food-for example, through research on their use of olfaction in both physical (Plotnik et al., 2014; Von Dürckheim et al., 2018) and social (Bates et al., 2007a,b) contexts-and why they decide to enter risky crop fields where they may encounter humans, as well as individual differences in their personalities (Yasui et al., 2012; Seltmann et al., 2018), life history traits and problem-solving abilities, conservation planners could focus mitigation on particular elephants.

In addition, instead of using particular strategies haphazardly to see what works in a given landscape, researchers could apply research on specific elephant groups and individual group leaders to the selection and identification of mitigation strategies that work best with particular types of elephants. We also hope that, in the future, research on individual differences in elephants and other species can be used to influence the animal's decisionmaking process (using techniques such as taste aversion or positive reinforcement conditioning) so that instead of forcing animals away from resources they desire or need, the animals make decisions on their own to avoid them. This would inevitably promote coexistence rather than conflict. Thus, in the case of the elephant, the complement of data on individual differences in life history, cognition and personality would allow conservationists to take the elephants' perspective to both look at the influences of particular traits on conflict as well as to potentially predict it before it occurs.

To be successful, however, this would require a comprehensive approach to wildlife management that accounted for the animals' needs so that alternative sources of food and water were available for animals away from human habitation. The feasibility of such an approach is problematic given that one of the reasons for increasing habitat fragmentation and encroachment is a decrease in natural resource availability for humans (Songer et al., 2016; Acharya et al., 2017). Nonetheless, we believe scientific 
research into behavior, ecology and cognition has great promise for helping develop new strategies to prevent conflict between humans and wildlife. When politicians, community leaders and conservationists alike recognize both our growing understanding of the individuality within animal species and the need to take both human- and wildlife-perspectives in conservation practice, current approaches to mitigating conflict will evolve away from short-term stop gap measures that temporarily avoid conflict and toward long-term solutions that effectively prevent it.

\section{AUTHOR CONTRIBUTIONS}

Both authors conceived, designed and wrote this work, and approved it for publication.

\section{REFERENCES}

Acharya, K. P., Paudel, P. K., Jnawali, S. R., Neupane, P. R., and Kohl, M. (2017). Can forest fragmentation and configuration work as indicators of humanwildlife conflict? Evidences from human death and injury by wildlife attacks in Nepal. Ecol. Indic. 80, 74-83. doi: 10.1016/j.ecolind.2017.04.037

Ale, S. B., and Brown, J. S. (2009). Prey behavior leads to predator: a case study of the Himalayan tahr and the snow leopard in Sagarmatha (Mt. Everest) Nat. Park Nepal Isr. J. Ecol. Evol. 55, 315-327. doi: 10.1560/IJEE.55.4.315

Asimopoulos, S. (2016). Human-Wildlife Conflict Mitigation in Peninsular Malaysia,Masters thesis, Swedish University of Agricultural Sciences.

Bal, P., Nath, C., Nanaya, K., Kushalappa, C., and Garcia, C. (2011). Elephants also like coffee: trends and drivers of human-elephant conflicts in coffee agroforestry landscapes of Kodagu, Western Ghats, India. Environ. Manage. 47, 789-801. doi: 10.1007/s00267-011-9636-1

Barrett, L. P., Stanton, L., and Benson-Amram, S. (in press). The cognition of 'nuisance' species. Anim. Behav. doi: 10.1016/j.anbehav.2018.05.005

Barua, M. (2014). Bio-geo-graphy: landscape, dwelling, and the political ecology of human-elephant relations. Environ. Plan. D Soc. Space 32, 915-934. doi: $10.1068 / \mathrm{d} 4213$

Barua, M., Bhagwat, S. A., and Jadhav, S. (2013). The hidden dimensions of human-wildlife conflict: health impacts, opportunity and transaction costs. Biol. Conserv. 157, 309-316. doi: 10.1016/j.biocon.2012.07.014

Bates, L. A., Lee, P. C., Njiraini, N., Poole, J. H., Sayialel, K., Sayialel, S., et al. (2008a). Do elephants show empathy? J. Conscious. Stud. 15, 204-225.

Bates, L. A., Poole, J. H., and Byrne, R. W. (2008b). Elephant cognition. Curr. Biol. 18, R544-R546. doi: 10.1016/j.cub.2008.04.019

Bates, L. A., Sayialel, K. N., Njiraini, N. W., Moss, C. J., Poole, J. H., and Byrne, R. W. (2007a). Elephants classify human ethnic groups by odor and garment color. Curr. Biol. 17, 1938-1942. doi: 10.1016/j.cub.2007.09.060

Bates, L. A., Sayialel, K. N., Njiraini, N. W., Poole, J. H., Moss, C. J., and Byrne, R. W. (2007b). African elephants have expectations about the locations of out-of-sight family members. Biol. Lett. 4, 34-36. doi: 10.1098/rsbl. 2007.0529

Berger-Tal, O., Blumstein, D. T., Carroll, S., Fisher, R. N., Mesnick, S. L., Owen, M. A., et al. (2015). A systematic survey of the integration of animal behavior into conservation. Conserv. Biol. 30, 744-753. doi: 10.1111/cobi. 12654

Berger-Tal, O., and Saltz, D. (2014). Using the movement patterns of reintroduced animals to improve reintroduction success. Curr. Zool. 60, 515-526. doi: $10.1093 /$ czoolo/60.4.515

Bulte, E. H., and Rondeau, D. (2005). Research and management viewpoint: why compensating wildlife damages may be bad for conservation. J. Wildl. Manage. 69, 14-19. doi: 10.2193/0022-541X(2005)069<0014:WCWDMB >2.0.CO;2

Caro, T. (2007). Behavior and conservation: a bridge too far? Trends Ecol. Evol. 22, 394-400. doi: 10.1016/j.tree.2007.06.003

\section{FUNDING}

HM is funded by a Society in Science-Branco Weiss Fellowship, administered by the ETH Zürich, a Fulbright Scholar Award, a College for Life Sciences Fellowship at the Wissenschaftskolleg zu Berlin, and a Drapers' Company Fellowship at Pembroke College. She thanks the Fischbeck Foundation for additional workshop funding. JP is funded by Hunter College, the Research Foundation of the City University of New York, the Golden Triangle Asian Elephant Foundation, and Elephant Family.

\section{ACKNOWLEDGMENTS}

We thank Frans de Waal and Nick Davies for comments on an earlier version of this manuscript, and Dalia Miller for assistance with researching the literature.

Caro, T., and Sherman, P. W. (2013). Eighteen reasons animal behaviourists avoid involvement in conservation. Anim. Behav. 85, 305-312. doi: 10.1016/j.anbehav.2012.11.007

Carter, N. H., Shrestha, B. K., Karki, J. B., Pradhan, N. M. B., and Liu, J. G. (2012). Coexistence between wildlife and humans at fine spatial scales. Proc. Natl. Acad. Sci. U.S.A. 109, 15360-15365. doi: 10.1073/pnas.1210490109

Chapman, S. N., Mumby, H. S., Crawley, J. A., Mar, K. U., Htut, W., Thura Soe, A., et al. (2016). How big is it really? Assessing the efficacy of indirect estimates of body size in Asian elephants. PLOS ONE 11:e0150533. doi: 10.1371/journal.pone.0150533

Charif, R. A., Ramey, R. R., Langbauer, W. R., Payne, K. B., Martin, R. B., and Brown, L. M. (2004). Spatial relationships and matrilineal kinship in African savanna elephant (Loxodonta africana) clans. Behav. Ecol. Sociobiol. 57, 327-338. doi: 10.1007/s00265-004-0867-5

Chartier, L., Zimmermann, A., and Ladle, R. J. (2011). Habitat loss and humanelephant conflict in Assam, India: does a critical threshold exist? Oryx 45, 528-533. doi: 10.1017/S0030605311000044

Chiyo, P. I., Lee, P. C., Moss, C. J., Archie, E. A., Hollister-Smith, J. A., and Alberts, S. C. (2011). No risk, no gain: effects of crop raiding and genetic diversity on body size in male elephants. Behav. Ecol. 22, 552-558. doi: 10.1093/beheco/arr016

Chiyo, P. I., Moss, C. J., and Alberts, S. C. (2012). The influence of life history milestones and association networks on crop-raiding behavior in male African elephants. PLOS ONE 7:e31382. doi: 10.1371/journal.pone.00 31382

Cook, R., Henley, M., and Parrini, F. (2015). Elephant movement patterns in relation to human inhabitants in and around the Great Limpopo Transfrontier Park. Koedoe 57:a1298. doi: 10.4102/koedoe.v57i1.1298

Cook, R. M., Parrini, F., King, L. E., Witkowski, E. T. F., and Henley, M. D. (2018). African honeybees as a mitigation method for elephant impact on trees. Biol. Conserv. 217, 329-336. doi: 10.1016/j.biocon.2017.11.024

Crawley, J.A.H., Mumby, H. S., Chapman, S. N., Lahdenperä, M., Mar, K. U., Htut, W., et al. (2017). Is bigger better? The relationship between size and reproduction in female Asian elephants. J. Evol. Biol. 30, 1836-1845. doi: $10.1111 /$ jeb. 13143

de Silva, S., Ranjeewa, A., and Kryazhimskiy, S. (2011). The dynamics of social networks among female Asian elephants. BMC Ecol. 11:17. doi: 10.1186/1472-6785-11-17

de Silva, S., and Wittemyer, G. (2012). A comparison of social organization in Asian elephants and African savannah elephants. Int. J. Primatol. 33, 1125-1141. doi: 10.1007/s10764-011-9564-1

Dickman, A. J. (2010). Complexities of conflict: the importance of considering social factors for effectively resolving human-wildlife conflict. Anim. Conserv. 13, 458-466. doi: 10.1111/j.1469-1795.2010.00368.x

Distefano, S. (2005). Human-Wildlife Conflict Worldwide: Collection of Case Studies, Analysis of Management Strategies and Good Practices. Rome, Italy: 
Food and Agricultural Organization of the United Nations (FAO), Sustainable Agriculture and Rural Development Initiative (SARDI).

Douglas-Hamilton, I., Bhalla, S., Wittemyer, G., and Vollrath, F. (2006). Behavioural reactions of elephants towards a dying and deceased matriarch. Appl. Anim. Behav. Sci. 100, 87-102. doi: 10.1016/j.applanim.2006.04.014

Dublin, H. T., and Hoare, R. E. (2004). Searching for solutions: the evolution of an integrated approach to understanding and mitigating human-elephant conflict in Africa. Hum. Dimens. Wildl. 9, 271-278. doi: 10.1080/10871200490505701

Dunham, K. M., Ghiurghi, A., Cumbi, R., and Urbano, F. (2010). Humanwildlife conflict in Mozambique: a national perspective, with emphasis on wildlife attacks on humans. Oryx 44, 185-193. doi: 10.1017/S00306053099 9086X

Evans, K., and Harris, S. (2012). Sex differences in habitat use by African elephants (Loxodonta africana) in the Okavango Delta, Botswana: is size really the deciding factor? Afr. J. Ecol. 50, 277-284. doi: 10.1111/j.1365-2028.2012.01 322.x

Fernando, P., Kumar, M. A., Williams, A. C., Wikramanayake, E., Aziz, T., and Singh, S. M. (2008). Review of Human-Elephant Conflict Mitigation Measures Practiced in South Asia. Gland: WWF.

Foerder, P., Galloway, M., Barthel, T., Moore, D. E. III, and Reiss, D. (2011). Insightful problem solving in an Asian elephant. PLOS ONE 6:e23251. doi: 10.1371 /journal.pone.0023251

Goldenberg, S. Z., Douglas-Hamilton, I., and Wittemyer, G. (2016). Vertical transmission of social roles drives resilience to poaching in elephant networks. Curr. Biol. 26, 75-79. doi: 10.1016/j.cub.2015.11.005

Goswami, V. R., Medhi, K., Nichols, J. D., and Oli, M. K. (2015). Mechanistic understanding of human-wildlife conflict through a novel application of dynamic occupancy models. Conserv. Biol. 29, 1100-1110. doi: $10.1111 /$ cobi.12475

Goswami, V. R., and Vasudev, D. (2017). Triage of conservation needs: the juxtaposition of conflict mitigation and connectivity considerations in heterogeneous, human-dominated landscapes. Front. Ecol. Evol. 4:144. doi: 10.3389/fevo.2016.00144

Greggor, A. L., Clayton, N. S., Phalan, B., and Thornton, A. (2014). Comparative cognition for conservationists. Trends Ecol. Evol. 29, 489-495. doi: 10.1016/j.tree.2014.06.004

Gunaryadi, D., Sugiyo, and Hedges, S. (2017). Community-based humanelephant conflict mitigation: the value of an evidence-based approach in promoting the uptake of effective methods. PLOS ONE 12:e0173742. doi: 10.1371 /journal.pone. 0173742

Hahn, N., Mwakatobe, A., Konuche, J., De Souza, N., Keyyu, J., Goss, M., et al. (2016). Unmanned aerial vehicles mitigate human-elephant conflict on the borders of Tanzanian Parks: a case study. Oryx 51, 513-516. doi: $10.1017 /$ S0030605316000946

Hoare, R. (2012). Lessons from 15 years of human-elephant conflict mitigation: management considerations involving biological, physical and governance issues in Africa. Pachyderm 51, 60-74.

Hoare, R. E. (1999). Determinants of human-elephant conflict in a land-use mosaic. J. Appl. Ecol. 36, 689-700. doi: 10.1046/j.1365-2664.1999.00437.x

Hoare, R. E. (2003). Fencing and Other Barriers Against Problem Elephants. AfESG Technical Brief Series.Available Online at: http://www.african-elephant.org/ hec/pdfs/hecfencen.pdf. [Accessed December 4, 2017].

Hoare, R. E., and Du Toit, J. T. (2001). Coexistence between people and elephants in African Savannas. Conserv. Biol. 13, 633-639. doi: 10.1046/j.1523-1739.1999.98035.x

Jackson, T. P., Mosojane, S., Ferreira, S. M., and Van Aarde, R. J. (2008). Solutions for elephant Loxodonta africana crop raiding in northern Botswana: moving away from symptomatic approaches. Oryx 42, 83-91. doi: $10.1017 /$ S0030605308001117

Jones, B., and Elliott, W. (2006). Human wildlife conflict in Namibia: experiences from a portfolio of practical solutions. Nat. Faune 21, 20-25.

King, L. E., Douglas-Hamilton, I., and Vollrath, F. (2011). Beehive fences as effective deterrents for crop-raiding elephants: field trials in northern Kenya. Afr. J. Ecol. 49, 431-439. doi: 10.1111/j.1365-2028.2011.01275.x

King, L. E., Lala, F., Nzumu, H., Mwambingu, E., and Douglas-Hamilton, I. (2017). Beehive fences as a multidimensional conflict-mitigation tool for farmers coexisting with elephants. Conserv. Biol. 31, 743-752. doi: 10.1111/cobi.12898
Kioko, J., Muruthi, P., Omondi, P., and Chiyo, P. I. (2008). The performance of electric fences as elephant barriers in Amboseli, Kenya. South Afr. J. Wildl. Res. 38, 52-58. doi: 10.3957/0379-4369-38.1.52

Langman, V. A., Rowe, M. F., Roberts, T. J., Langman, N. V., and Taylor, C. R. (2012). Minimum cost of transport in Asian elephants: do we really need a bigger elephant? J. Exp. Biol. 215, 1509-1514. doi: 10.1242/jeb.063032

Le Bel, S., La Grange, M., and Drouet, N. (2015). Repelling elephants with a chilli pepper gas dispenser: field tests and practical use in Mozambique, Zambia and Zimbabwe from 2009 to 2013. Pachyderm 87-96.

Lee, P., and Moss, C. (1999). "The social context for learning and behavioural development among wild African elephants," in Mammalian Social Learning: Comparative and Ecological Perspective. Cambridge University Press, eds B. Ho, and G. Kr (Cambridge: Cambridge University Press), 102-125.

Lee, P. C., Lindsay, W. K., and Moss, C. J. (2011). "Ecological patterns of variability in demographic rates," in The Amboseli Elephants, eds C. J. Moss, H. Croze, and P. C. Lee (Chicago, IL: University of Chicago Press), 74-88.

Lee, P. C., and Moss, C. J. (2012). Wild female African elephants (Loxodonta africana) exhibit personality traits of leadership and social integration. J. Comp. Psychol. 126, 224-232. doi: 10.1037/a0026566

Lynsdale, C. L., Mumby, H. S., Hayward, A. D., Mar, K. U., and Lummaa, V. (2017). Parasite-associated mortality in a long-lived mammal: variation with host age, sex, and reproduction. Ecol. Evol. 7, 10904-10915. doi: 10.1002/ece3.3559

McComb, K., Baker, L., and Moss, C. (2005). African elephants show high levels of interest in the skulls and ivory of their own species. Biol. Lett. 2, 26-28. doi: 10.1098/rsbl.2005.0400

McComb, K., Moss, C., Durant, S. M., Baker, L., and Sayialel, S. (2001). Matriarchs as repositories of social knowledge in African elephants. Science 292, 491-494. doi: $10.1126 /$ science. 1057895

McComb, K., Shannon, G., Durant, S. M., Sayialel, K., Slotow, R., Poole, J., et al. (2011). Leadership in elephants: the adaptive value of age. Proc. R. Soc. B: Biol. Sci. 278, 3270-3276. doi: 10.1098/rspb.2011.0168

McComb, K., Shannon, G., Sayialel, K. N., and Moss, C. (2014). Elephants can determine ethnicity, gender, and age from acoustic cues in human voices. Proc. Natil. Acad. Sci. U.S.A. 111, 5433-5438. doi: 10.1073/pnas.1321543111

Midgley, J. J., Balfour, D., and Kerley, G. I. (2005). Why do elephants damage savanna trees? S. Afr. J. Sci. 101, 213-215.

Mumby, H. S., Mar, K. U., Hayward, A. D., Htut, W., Htut-Aung, Y., and Lummaa, V. (2015). Elephants born in the high stress season have faster reproductive ageing. Sci. Rep. 5:13946. doi: 10.1038/srep13946

Nelson, A., Bidwell, P., and Sillero-Zubiri, C. (2003). A Review of HumanElephant Conflict Management Strategies. People and Wildlife Initiative. Oxford University: Wildlife Conservation Research Unit.

Ngama, S., Korte, L., Bindelle, J., Vermeulen, C., and Poulsen, J. R. (2016). How bees deter elephants: beehive trials with forest elephants (Loxodonta africana cyclotis) in Gabon. PLoS ONE 11:e0155690. doi: 10.1371/journal.pone.0155690

O'Connell-Rodwell, C. E., Rodwell, T., Rice, M., and Hart, L. A. (2000). Living with the modern conservation paradigm: can agricultural communities co-exist with elephants? A five-year case study in East Caprivi, Namibia. Biol. Conserv. 93, 381-391. doi: 10.1016/S0006-3207(99)00108-1

Osborn, F. V., and Parker, G. E. (2002). Community-based methods to reduce crop loss to elephants: experiments in the communal lands of Zimbabwe. Pachyderm $33,32-38$.

Peterson, M. N., Birckhead, J. L., Leong, K., Peterson, M. J., and Peterson, T. R. (2010). Rearticulating the myth of human-wildlife conflict. Conserv. Lett. 3, 74-82. doi: 10.1111/j.1755-263X.2010.00099.x

Plotnik, J. M., and de Waal, F. B. M. (2014). Asian elephants (Elephas maximus) reassure others in distress. Peer J. 2:e278. doi: 10.7717/peerj.278

Plotnik, J. M., Lair, R., Suphachoksahakun, W., and De Waal, F. B. M. (2011). Elephants know when they need a helping trunk in a cooperative task. Proc Natl. Acad. Sci.U.S.A. 108, 5116-5121. doi: 10.1073/pnas.1101765108

Plotnik, J. M., Shaw, R. C., Brubaker, D. L., Tiller, L. N., and Clayton, N. S. (2014). Thinking with their trunks: elephants use smell but not sound to locate food and exclude nonrewarding alternatives. Anim. Behav. 88, 91-98. doi: 10.1016/j.anbehav.2013.11.011

Poole, J. H. (1989). Mate guarding, reproductive success and female choice in African elephants. Anim. Behav. 37, 842-849. doi: 10.1016/0003-3472(89)90068-7 
Poole, J. H., Tyack, P. L., Stoeger-Horwath, A. S., and Watwood, S. (2005). Animal behaviour: elephants are capable of vocal learning. Nature 434, 455-456. doi: $10.1038 / 434455 a$

Raihan Sarker, A. H. M., and Røskaft, E. (2010). Human-wildlife conflicts and management options in Bangladesh, with special reference to Asian elephants (Elephas maximus). Int. J. Biodivers. Sci. Ecosyst. Serv. Manage. 6, 164-175. doi: 10.1080/21513732.2011.554867

Reiches, M. W., Ellison, P. T., Lipson, S. F., Sharrock, K. C., Gardiner, E., and Duncan, L. G. (2009). Pooled energy budget and human life history. Am. J. Hum. Biol. 21, 421-429. doi: 10.1002/ajhb. 20906

Rode, K. D., Chiyo, P. I., Chapman, C. A., and Mcdowell, L. R. (2006). Nutritional ecology of elephants in kibale national park, uganda, and its relationship with crop-raiding behaviour. J. Trop. Ecol. 22, 441-449. doi: 10.1017/S0266467406003233

Seltmann, M. W., Helle, S., Adams, M. J., Mar, K. U., and Lahdenperä, M. (2018). Evaluating the personality structure of semi-captive Asian elephants living in their natural habitat. R. Soc. Open Sci. 5:172026. doi: 10.1098/rsos. 172026

Shannon, G., Page, B. R., Mackey, R. L., Duffy, K. J., and Slotow, R. (2008). Activity budgets and sexual segregation in African elephants (Loxodonta africana). J. Mammal. 89, 467-476. doi: 10.1644/07-MAMM-A132R.1

Shier, D. M., and Swaisgood, R. R. (2012). Fitness costs of neighborhood diruption in translocations of a solitary mammal. Conserv. Biol. 26, 116-123. doi: 10.1111/j.1523-1739.2011.01748.x

Songer, M., Aung, M., Allendorf, T. D., Calabrese, J. M., and Leimgruber, P. (2016). Drivers of change in Myanmar's wild elephant distribution. Trop. Conserv. Sci. 9, 1-10. doi: 10.1177/1940082916673749

Songhurst, A., Mcclloch, G., and Coulson, T. (2016). Finding pathways to human-elephant coexistence: a risky business. Oryx 50, 713-720. doi: 10.1017/S0030605315000344

Sri Lanka Wildlife Conservation Society (2015). Project Orange Elephant.Available online at: http://www.slwcs.org/\#!project-orange-elephant/clj79 [Accessed 27 June, 2016].

Srinivasaiah, N. M., Anand, V. D., Vaidyanathan, S., and Sinha, A. (2012). Usual populations, unusual individuals: insights into the behavior and management of Asian elephants in fragmented landscapes. PLOS ONE 7:e42571. doi: 10.1371/journal.pone.0042571

Sukumar, R., and Gadgil, M. (1988). Male-female differences in foraging on crops by Asian elephants. Anim. Behav. 36, 1233-1235. doi: 10.1016/S0003-3472(88)80084-8
Van Aarde, R., Whyte, I., and Pimm, S. (1999). Culling and the dynamics of the Kruger National Park African elephant population. Anim. Conserv. 2, 287-294. doi: 10.1111/j.1469-1795.1999.tb00075.x

Von Dürckheim, K. E. M., Hoffman, L. C., Leslie, A., Hensman, M. C., Hensman, S., Schultz, K., et al. (2018). African elephants (Loxodonta africana) display remarkable olfactory acuity in human scent matching to sample performance. Appl. Anim. Behav. Sci. 200, 123-129. doi: 10.1016/j.applanim.2017.12.004

Wahed, M. A., Ullah, M. R., and Haseeb, M. I. (2016). Human-Elephant Conflict Mitigation Measures: Lessons From Bangladesh. Dhaka, Bangladesh: IUCN.

Wiafe, E. D., and Sam, M. K. (2014). Evaluation of a low-tech method, peppergrease, for combatting elephant crop-raiding activities in Kakum Conservation Area, Ghana. Pachyderm 55, 38-42.

Wilson, S., Davies, T. E., Hazarika, N., and Zimmermann, A. (2015). Understanding spatial and temporal patterns of human-elephant conflict in Assam, India. Oryx 49, 140-149. doi: 10.1017/S0030605313000513

Wittemyer, G., Getz, W. M., Vollrath, F., and Douglas-Hamilton, I. (2007). Social dominance, seasonal movements, and spatial segregation in African elephants: a contribution to conservation behavior. Behav. Ecol. Sociobiol. 61, 1919-1931. doi: 10.1007/s00265-007-0432-0

Yasui, S., Konno, A., Tanaka, M., Idani, G. I., Ludwig, A., Lieckfeldt, D., et al. (2012). Personality assessment and its association with genetic factors in captive Asian and African elephants. Zoo Biol. 32, 70-78. doi: 10.1002/zoo.21045

Zeppelzauer, M., and Stoeger, A. S. (2015). Establishing the fundamentals for an elephant early warning and monitoring system. BMC Res. Notes 8:409. doi: 10.1186/s13104-015-1370-y

Zimmermann, A., Davies, T. E., Hazarika, N., Wilson, S., Chakraborty, J., Hazarika, B., et al. (2009). Community-based human-elephant conflict management in Assam. Gajah 30, 34-40.

Conflict of Interest Statement: JP is the founder and executive director of Think Elephants International, a US public charity that focuses on elephant conservation.

The remaining author declares that the research was conducted in the absence of any commercial or financial relationships that could be construed as a potential conflict of interest.

Copyright (c) 2018 Mumby and Plotnik. This is an open-access article distributed under the terms of the Creative Commons Attribution License (CC BY). The use, distribution or reproduction in other forums is permitted, provided the original author(s) and the copyright owner(s) are credited and that the original publication in this journal is cited, in accordance with accepted academic practice. No use, distribution or reproduction is permitted which does not comply with these terms. 